\title{
Semiconductor Lasers Using Diffused Quantum-Well Structures
}

\author{
S.-F. Yu and E. Herbert Li, Senior Member, IEEE
}

(Invited Paper)

\begin{abstract}
We assess the relative merits and prospects of using diffused quantum-well (QW) structures in semiconductor lasers. First, different techniques to achieve interdiffusion are analyzed and compared. Second, recent development of semiconductor lasers using interdiffusion technique is also discussed. Third, the optical properties of diffused QW's are studied. In addition, novel design of diffused QW's structures to maintain stable singlemode operation in semiconductor lasers is proposed. Finally, brief discussion and conclusion are given.
\end{abstract}

Index Terms - Quantum-well intermixing, quantum wells, semiconductor lasers.

\section{INTRODUCTION}

$\mathbf{I}$ NTERDIFFUSION of quantum wells (QW's) is a very important emerging technology for the fabrication of semiconductor lasers, because it can be utilized to improve the electrical and optical properties of the devices. Selective interdiffusion can be achieved by masking into the desired regions of a QW wafer. Modification of electrical conductivity and refractive index will be resulted between the as-grown and the disordered regions. This technology enables a planar process leading to improvement of the lateral electrical and optical confinement of semiconductor lasers such that low threshold current and single lateral-mode operation can be obtained [1]-[5]. Furthermore, interdiffusion between QW and adjacent barriers results in a change in the shape of QW. This in-turn modifies the subband energy in conduction and valence bands, resulting in the modification of interband transition energy. Therefore, interdiffusion technique has been used to fabricate multiple wavelength QW lasers without using the complicated processes of etching or epitaxial regrowth [6], [7]. Other advantages of using interdiffusion techniques are 1) simple and 2) compatible with the existing fabrication technologies of semiconductor lasers.

There are two kinds of interdiffusion techniques used widely. One is the impurity-induced interdiffusion (IID), while the other is the impurity-free vacancy diffusion (IFVD) [8]. IID technique involves impurities to realize interdiffusion for the substantial change in refractive index and electrical conductivity [1]-[5]. This technique is commonly used to achieve lateral electrical and optical confinement in

Manuscript received January 20, 1998; revised April 28, 1998. This work was supported by a HKU-CRCG grant and RGC grant.

The authors are with the Department of Electrical and Electronic Engineering, University of Hong Kong, Pokfulam Road, Hong Kong.

Publisher Item Identifier S 1077-260X(98)05850-X. semiconductor lasers. On the other hand, IFVD involves no impurities to obtain interdiffusion such that the electrical properties of the diffused QW's are conserved. This technique is usually used to fabricate multiple wavelength tuning lasers [6], [7] and laser-modulator [9], [10].

In this paper, we summarize the existing techniques to realize diffused QW and the use of interdiffusion techniques to fabricate semiconductor lasers. Furthermore, the possibilities of using diffused QW to maintain stable single-mode operation in semiconductor lasers are proposed and discussed. This paper is organized as follows: IID and IFVD techniques to realize diffused QW's are discussed in Sections II and III, respectively. Section IV gives the recent examples of using interdiffusion to fabricate QW's semiconductor lasers. Theoretical studies of diffused QW's is given in Section V. The use of diffused QW's in design of semiconductor lasers for single-mode operation is discussed in Section VI. Discussion and conclusion are given in Section VII.

\section{INTERDIFFUSION TECHNIQUE-IID}

The technique to enhance intermixing rate of an as-growth QW through the implantation and diffusion of impurities is called IID [8]. IID converts QW heterostructure into a uniform alloy of averaged composition. As a result, the compositional distribution of QW changes from square to nonsquare profile, which in turns modifies the band structure as well as the refractive index of the QW material [11]. In the following paragraphs, the fabrication process of IID, the selection of QW heterostructure and implanted impurities as well as their applications in fabrication of semiconductor lasers are discussed.

\section{A. Fabrication Process of Impurities Induced Compositional Disordering}

The IID technique consists of: 1) implantation of impurities into the QW heterostructure and 2) rapid thermal annealing (RTA). The implantation process can be achieved by injection of species with kinetic energy and concentration varying from $1 \mathrm{keV}$ to $10 \mathrm{MeV}$, and $10^{10}$ to $10^{16}$ ions $/ \mathrm{cm}^{2}$, respectively, into the $\mathrm{QW}$ heterostructure. The degree of disordering can be controlled by the energy of the implanted species. In addition, this technology enables a planar process because selective implantation can be achieved by masking into the desired regions [1]-[4]. It is noted that the implanted impurities enhance the interdiffusion rate which is directly proportional 
to the amount of implanted dose. After implantation, the material will go through RTA. The annealing process will usually last for several seconds with temperature ranging from $900{ }^{\circ} \mathrm{C}$ to $1130{ }^{\circ} \mathrm{C}$. The material has to go through RTA in order to 1) increase the interdiffusion rate of the injected species and 2) repair the damaged lattice resulted from the bombardment of impurities. It is observed that the degree of damage on the lattice structure increases with the increase of the implantation energy. Therefore, careful selection of impurities with suitable implanted energy and concentration is required for the fabrication of diffused QW lasers.

\section{B. Implantation Impurities and QW Heterostrcuture Systems}

IID can be achieved in heterostructure QW systems such as GaAs-AlGaAs [2], [3], [9]-[11] and InGaAs-GaAs [1], [4], [5], [12]-[14] with suitable selection of impurities. The corresponding impurities commonly used in the IID process are the zinc, silicon, and oxygen. The impurities used for disordering the heterostructure QW can be divided into two major categories: 1) electrically active and 2) neutral. Examples of electrical active species are zinc (p-type ions) and silicon (ntype ions) [2], [4], [5], [12], while neutral impurities are boron, fluorine and oxygen [15]. For the electrically active impurities, the most commonly used p-type dopant is zinc [16], [17], while the n-type dopant is silicon [18]-[20]. It has been shown that the lateral optical confinement of buried heterostructure QW lasers can be realized by selective interdiffusion of zinc [16], [17] or silicon [18]-[20] to disorder the active region in the standard planar QW materials [6]. However, the adverse effects of using zinc or silicon IID process are: 1) the requirement of long annealing time and 2) the enhancement of free-carrier absorption losses. For the neutral impurities, the typically used species are argon, boron, and fluorine [3], [21]. It is noted that neutral impurities are commonly used in IID process to reduce: 1) optical losses and 2) leakage current in grating sections of the distributed Bragg reflector (DBR) lasers. Comparing with the electrically active species, the neutral impurities exhibit less free-carrier absorption losses as well as high electrical resistivity in the disordered areas.

\section{Advantages and Disadvantages of Using IID}

IID is a relatively simpler and repeatable fabrication process. This is because IID only requires impurity diffusion or implantation into the QW structure, followed by RTA to repair the damaged lattice. During the interdiffusion process, the local bandgap increases but the corresponding refractive index reduces [2], [12]. It is because under the influence of injected impurities, the compositional profile of $\mathrm{QW}$ is altered from square to nonsquare profile. In fact, this modification of bandgap and refractive index can be utilized to realize semiconductor lasers in a planar configuration. As we can see, the lateral confinement of optical wave can be obtained by IID due to the variation of refractive index. In addition, the reduction of electrical conductivity due to the penetration of impurities can also be used to enhance lateral confinement of injection current such that threshold current can be reduced. On the other hand, shift of bandgap provides a possibility to tune the operation wavelength of the laser from a single wafer [22]-[24]. Thus, IID is a very powerful method to realize semiconductor lasers in a simple and efficient manner.

However, the main disadvantage of IID is the reduction of residual purity and crystalline quality such that the optical absorption is also increased. Also, there will be unwanted change in the material resistivity and trap concentrations. Although the implantation or diffusion of impurities enhances the interdiffusion rate of $\mathrm{QW}$ material, the impurities would inevitably cause damage to the lattice. Therefore, these undesirable side effects should be minimized for the fabrication of diffused QW lasers.

\section{INTERDIFFUSION TECHNIQUE-IMPURITY-FREE VACANCY DIFFUSION}

IFVD is a simple process that controls the degree of disordering in QW materials by the diffusion of vacancies. There are several methods to achieve IFVD, namely: 1) $\mathrm{SiO}_{2}-\mathrm{Si}_{3} \mathrm{~N}_{4}$ induced interdiffusion GaAs-AlGaAs system [25]-[31]; 2) anodic-oxide-induced interdiffusion in GaAs-AlGaAs systems [32]; and 3) photoabsorption-induced interdiffusion (i.e., laser intermixing) in InGaAs-InGaAsP systems [6], [7], [33]. It must be noted that method 1) and 2) are similar and the only difference is the formation of capping layer. However, method 3) is different to 1) and 2) because it uses laser beam to carry out the interdiffusion process instead of using thermal annealing.

\section{A. $\mathrm{SiO}_{2}-\mathrm{Si}_{3} \mathrm{~N}_{4}$ Induced Interdiffusion}

$\mathrm{GaAs}$ is encapsulated by a dielectric capping layer, which can be $\mathrm{SiO}_{2}$ or $\mathrm{Si}_{3} \mathrm{~N}_{4}$, deposited on the surface of the GaAs-AlGaAs heterostructure QW material. Function of the dielectric layer is to enhance the out-diffusion rate of the group-III atom, gallium. The out-diffusion of gallium atoms is partially due to its: 1) high diffusion coefficient and 2) solubility in the dielectric capping layer. During RTA at $900{ }^{\circ} \mathrm{C}$ or higher temperature, the out-diffusion of gallium atoms generate group-III vacancies. In addition, the outdiffusion rate of gallium atoms is enhanced by the interface stress between the $\mathrm{SiO}_{2}-\mathrm{Si}_{3} \mathrm{~N}_{4}$ and $\mathrm{GaAs}$ layers due to their large difference of thermal expansion coefficients. On the other hand, the resulting group-III vacancies promote the diffusion of aluminum and gallium atoms into the buried GaAs QW and AlGaAs barriers, respectively. Therefore, interdiffusion occurs at the interface of the QW heterostructure. Consequently, the shape of QW is distorted, resulting in widening of material bandgap and reduction of refractive index. Furthermore, the gain and the absorption spectra are also changed [25], [26].

The out-diffusion rate of gallium atoms depends on 1) thickness and 2) porosity of the dielectric capping layer. The spatial control of the bandgap of the QW material can be achieved by varying the thickness of the dielectric capping layer. Alternatively, the out-diffusion rate of gallium atoms can also be enhanced with the increase of oxygen content inside the $\mathrm{SiO}_{2}$ dielectric cap. However, thickness control of the dielectric capping layer requires number of processing steps and it is not reproducible in practice [27]. In addition, it is 


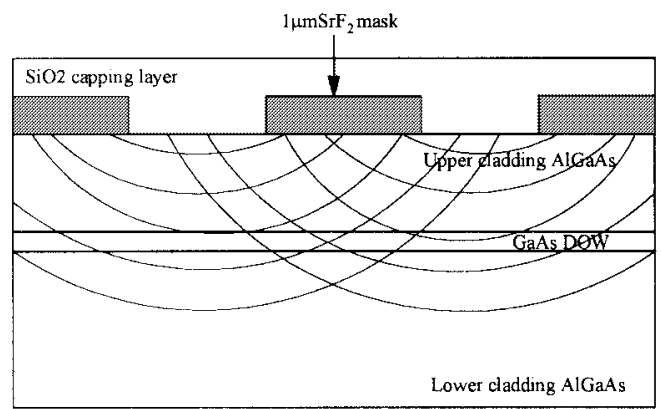

Fig. 1. Schematic of vacancy diffusion profile in $\mathrm{SrF}_{2}$ masked $\mathrm{QW}$ material.

difficult to vary the chemical composition of the dielectric capping layer.

In order to solve the above-mentioned problems and to achieve spatial control of degree of interdiffusion, a modified technique based on the above IFVD technique, called selective intermixing in selected areas is developed [28], [29]. In the process, the wafer is patterned using electron beam lithography or by combination of photolithography with wet chemical etching, utilizing micrometer-sized features of $\mathrm{SrF}_{2}$ to act as a bandgap control mask [28]. The sample is then deposited with dielectric cap layer using $\mathrm{SiO}_{2}$ or $\mathrm{Si}_{3} \mathrm{~N}_{4}$, see Fig. 1. As the degree of intermixing depends on the area of semiconductor surface in direct contact with the cap layer, it is possible to control spatially the amount of bandgap shifting in QW using a single RTA step and to obtain a range of uniform bandgap values.

With a view to achieve uniform disordering and intermixing at the QW depth by overlapping the diffusion regions, the dimensions of the $\mathrm{SrF}_{2}$ mask have to be smaller than or comparable to the diffusion length of the point defects. It was examined that the dimension of the $\mathrm{SrF}_{2}$ mask should be around $3 \mu \mathrm{m}$ for QW of 1- $\mu \mathrm{m}$ depth such that high mobility for vacancies and large diffusion constant can be obtained [28], [29].

\section{B. Anodic-Oxide-Induced Interdiffusion}

The technique of anodic-oxide induced interdiffusion is similar to $\mathrm{SiO}_{2}-\mathrm{Si}_{3} \mathrm{~N}_{4}$ induced interdiffusion except 1) the formation procedures and 2) the material used for the capping layer are different [32]. This technique is commonly applied to QW materials such as GaAs-AlGaAs and InGaAs-GaAs systems due to the requirement of oxidation of GaAs. The process of anodic-oxide-induced interdiffusion starts by oxidation of selected portion of GaAs cap layer anodically at room temperature for several minutes. The surface of GaAs can be patterned before anodization in order to achieve selective area interdiffusion. Besides, electrically pulsed anodic-oxide is used as the cap layer promoting interdiffusion in QW beneath the cap. The oxide layer, being insensitive to the current range examined, helps to increase the interdiffusion rate at high temperature. The material then goes through the RTA process to achieve interdiffusion which is done in a flowing inert gas.

The anodic-oxide-induced interdiffusion technique is simple, reliable, and inexpensive. It can be applied in the creation of current blocking layers for the fabrication of ridgewaveguide QW lasers. Also, it can be used for the fabrication
TABLE I

QuANTITATIVE COMPaRISONS BETWEen IID AND IFVD

\begin{tabular}{|c|c|c|}
\hline Items & IID & IFVD \\
\hline $\begin{array}{l}\text { Blue shift of } \\
\text { absorption edge or } \\
\text { photoluminescence }\end{array}$ & $\begin{array}{l}\mathrm{GaAs} / \mathrm{AlGaAs} \mathrm{QW} \text { (impurities - } \\
\mathrm{F} / \mathrm{Br} \text { ) up to } 100 \mathrm{meV}[22] \\
\text { InGaAs/GaAs QW (impurity } \mathrm{As}^{+} \text {) } \\
\text { up to } 67 \mathrm{meV}[24] \\
\text { InGaAs/InP QW (impurity } \mathrm{P}^{+} \text {) up } \\
\text { to } 32 \mathrm{meV}[23]\end{array}$ & $\begin{array}{l}\text { GaAs/AlGaAs QW (using } \mathrm{SrF}_{2} \text { mask) } \\
\text { up to } 92 \mathrm{meV} \text { [27] } \\
\text { InGaAs/nGaAsP (PAID) up to } 160 \mathrm{~nm} \\
(\sim 82 \mathrm{meV})[6],[7] \text {. }\end{array}$ \\
\hline Absorption loss & $\begin{array}{l}\mathrm{GaAs} / \mathrm{AlGaAs} \mathrm{QW} \text { with impurity } \\
\mathrm{F} \text { is around } 6 \mathrm{~dB} \mathrm{~cm} \text { and with } \\
\text { impurity } \mathrm{Br} \text { is around } 15 \mathrm{~dB} \mathrm{~cm}^{-1} \\
\text { at } 885 \mathrm{~nm}[2.2]\end{array}$ & $\begin{array}{l}\mathrm{GaAs} / \mathrm{AlGaAs} \mathrm{QW} \text { (using } \mathrm{SrF}_{2} \text { mask) } \\
\text { around } 8.5 \mathrm{~dB} \mathrm{~cm}^{-1} \text { in between } 850 \\
\text { and } 890 \mathrm{~nm}[29] . \\
\\
\text { InGaAs/InGaAsP QW (PAID) around } \\
5 \mathrm{~dB} \mathrm{~cm}^{-1} \text { at } 1550 \mathrm{~nm} \text { [6],[7]. }\end{array}$ \\
\hline
\end{tabular}

of nonabsorbing mirrors for high-power laser and multiple wavelength lasers.

\section{Photoabsorption-Induced Interdiffusion}

The use of laser annealing in photoabsorption-induced disordering (PAID) is the main difference to the use of thermal annealing in IID and IFVD [6], [7], [33]. PAID is a promising technique to achieve disordering in InGaAs-InGaAsP QW material due to the poor thermal stability in InGaAsP. In the disordering process, a layer of plasma-deposited $\mathrm{SiO}_{2}$ of about $500 \mathrm{~nm}$ thick is used to coat on the wafer. The $\mathrm{SiO}_{2}$ layer acts as: 1) an antireflection coating; 2) a protective layer against reactions with atmosphere at surface; and 3) a prevention layer to avoid the desorption of $P$ from the sample. It must be noted that the thick $\mathrm{SiO}_{2}$ can protect the surface of the sample during high temperature annealing, but this $\mathrm{SiO}_{2}$ dielectric capping layer will not undergo IFVD at the temperature used in PAID process.

The sample is placed on polished ceramic on a hot-plate at about $220^{\circ} \mathrm{C}$. It is because the power density of the incident laser needed to heat the sample to the temperature where disordering occurs will be reduced significantly by the increase of background temperature. Another advantage of using ceramic is that its low thermal conductivity also helps in reducing the required power density of laser beam. Therefore, the irradiation of laser light of $5 \mathrm{~W} / \mathrm{mm}^{2}$ power density for around $30 \mathrm{~min}$ is sufficient to achieve intermixing.

The PAID technique is an effective way to produce InGaAs-InGaAsP systems with controllable bandgap tuning. It is shown that large blue-shift of the photoluminescence peak energy can be obtained in standard QW laser structure with partially intermixed. In addition, the threshold current densities and internal quantum efficiencies are found to be comparable to that of the as-grown material, indicating that the material is of good quality and can be applied in integration of devices [6], [7], [33].

\section{Advantages and Disadvantages of Using Impurity-Free Vacancy Diffusion}

In general, the technique of IFVD is more suitable for the fabrication of semiconductor lasers than IID, especially for 
devices which only require the change of refractive index. Using IFVD, no penetration of impurities is required and the quality of the QW material is not degraded because there are: 1) no reduction of electrical conductivity of the QW material; 2) no increase of optical losses inside the interdiffusion region; and 3) no significant change in transparency current, internal quantum efficiency or internal propagation loss of the $\mathrm{QW}$ material [25]-[31]. Hence, the electrical and optical properties of the QW material are conserved using IFVD. A quantitative comparisons between IID and IFVD is given in Table I. However, there are two major problems arising from the use of $\mathrm{SiO}_{2}$ and $\mathrm{Si}_{3} \mathrm{~N}_{4}$ as the capping layer of the GaAs-AlGaAs system: 1) $\mathrm{SiO}_{2}$ will react with $\mathrm{Al}$ when in direct contact with $\mathrm{AlGaAs}$ such that $\mathrm{Si}$ will be generated as an impurity source and 2) IFVD will cause considerable strain to GaAs-AlGaAs system when $\mathrm{Si}_{3} \mathrm{~N}_{4}$ is used as the capping layer.

The main advantage of PAID technique is its selective interdiffusion of different QW layers. PAID is not restricted to structure of QW's with surface or near-surface multilayers, as the disordering process is not limited by the diffusion length or implantation depth of impurities as if in IID. However, the power densities required to melt the material can introduce thermal shock damage if a pulsed mode is in used. It can cause a potentially undesirable redistribution of dopants outside the active region of the device [33].

\section{APPLICATION OF INTERDIFFUSION TECHNIQUE IN FABRICATION OF SEMICONDUCTOR LASERS}

Interdiffusion of QW is a simple, controllable and reproducible technique to change the as-grown $\mathrm{QW}$ into nonsquare one. In general, the intermixing process causes the increment in bandgap energy but the reduction in refractive index of the QW materials. The resistivity of the QW material can also be enhanced by using IID technique. These features of diffused QW's allow the lateral confinement of carrier density and light selectively at different locations in the wafer. Therefore, interdiffusion technique is an attractive way to fabricate twoand three-dimensional integrated optoelectronics devices such as waveguides and lasers on a single substrate [7], [9], [18], [20], [30]. Interdiffusion technique further simplifies the fabrication procedures of semiconductor lasers because the lateral confinement of carrier concentration and optical field can be achieved without the requirement of regrowth as in the semiconductor lasers with buried heterostructure or ridge waveguide [34]. In the following paragraphs, the use of interdiffusion techniques to fabricate semiconductor lasers are discussed.

\section{A. Lateral Optical and Electrical Confinement Using IID Technique-Active Impurities}

IID technique can be utilized to define lateral optical and electrical confinement structure for facet emitting devices [1]-[6], [9], [10], [35]-[39]. This can be done by selectively diffusing zinc or silicon to disorder the active region in standard planar multiple QW wafer. This structure design eliminates the need for the narrow stripe contact, thus resulting in low beam divergence and single lateral mode operation. Furthermore, this fabrication technique of lasers is simple

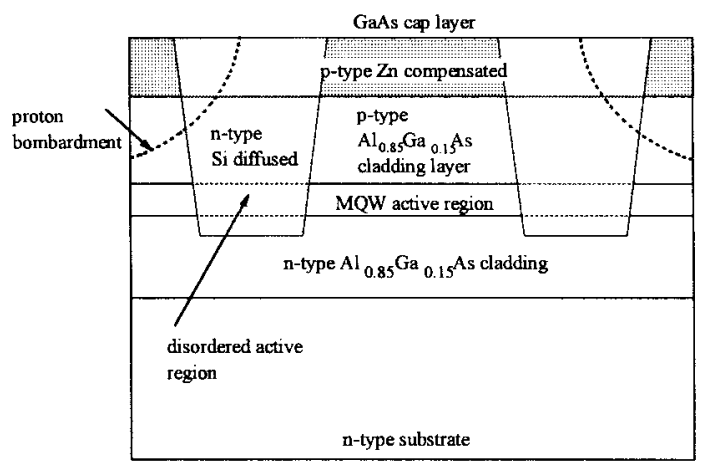

Fig. 2. Schematic diagram of buried heterostructure laser fabricated by silicon-IID.

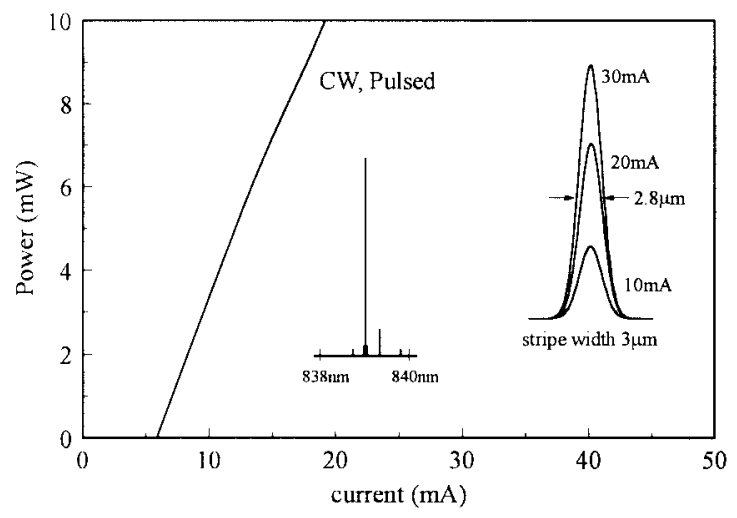

Fig. 3. Pulsed and CW power/current characteristics for device with $3-\mu \mathrm{m}$-wide active region.

and does not need complicated epitaxial regrowth steps or deposited insulating layer.

Fig. 2 illustrates the geometry of a buried heterostructure GaAs-AlGaAs QW's laser fabricated by silicon IID to improve the lateral electrical and optical confinement [2]. Inside the active layer, there are two coupled QW's embedded in a separate confinement heterostructure on an n-type substrate. The IID process starts by depositing a layer of $\mathrm{Si}_{3} \mathrm{~N}_{4}$, which is patterned photolithographically to provide windows for diffusion of silicon. Diffusion of silicon is done by heating the sample at $850{ }^{\circ} \mathrm{C}$ for $7.5 \mathrm{~h}$. The active layer is disordered in the areas adjacent to what will eventually become the lasing filament. The sample will undergo zinc diffusion such that the parasitic junction will lie in the high aluminum cladding layer. At this junction, the bandgap of the material is significantly higher than that at the active GaAs junction such that the junction's conductivity is significantly reduced. Therefore, compared with the total current flowing, the leakage current through the high aluminum junction is only a very small fraction. Hence, the performance of the device is not degraded. Fig. 3 exhibits the light current and near-field characteristics of the device with $3-\mu \mathrm{m}$-wide active region [2]. It is seen that the laser operating at stable fundamental lateral and nearly single longitudinal mode. Hence, the near-field properties of narrower stripe devices are improved. Furthermore, it is demonstrated that free-carrier absorption effects in the silicon diffused regions and optical absorption of scattering losses due to ordered-disordered material interfaces are minimal. Therefore, 


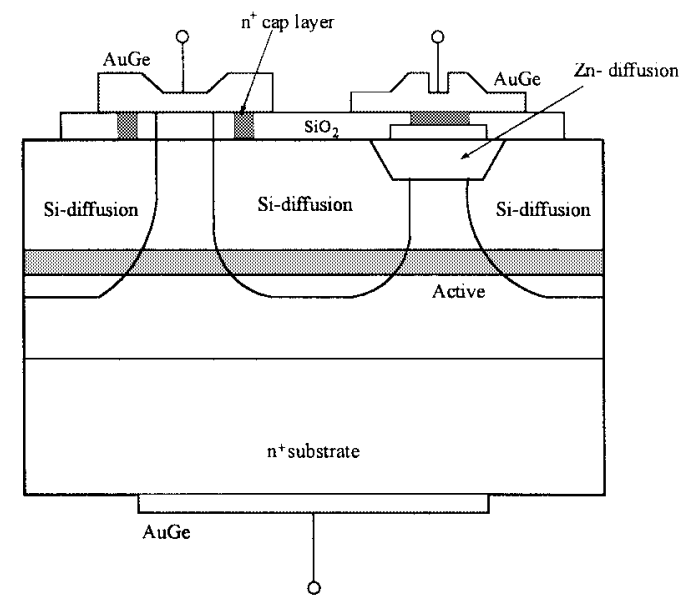

Fig. 4. Schematic of laterally injected laser fabricated by IID.

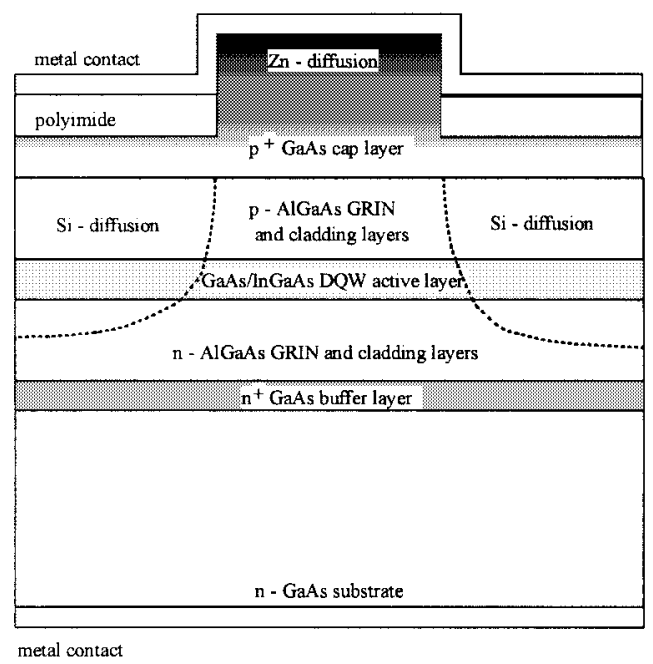

Fig. 5. Schematic of an IID-ridge waveguide laser.

silicon IID is an excellent candidate in modifying the optical behavior of QW material and suitable for fabrication of lasers.

IID technique is also commonly used to improve the lateral current injection confinement in semiconductor lasers. It is shown that lateral injected lasers [37] and ridge waveguide (RW) lasers [35], [38] using IID technique to enhance lateral carrier confinement such that the threshold current is reduced and output power level is enhanced. Fig. 4 shows the schematic of lateral injected GaAs-AlGaAs QW's lasers fabricated by IID technique [37]. Its fabrication process is similar to that given in the above paragraph, except that AuGe-Ni-Au films are evaporated onto the top surface of the sample. These films become ohmic contacts on the n-type and p-type layers which enable the laser to be injected laterally through the top n-type contact, or vertically through the bottom n-type contact. The purpose of using silicon is to confine the injection carrier laterally, while using zinc is to increase the conductivity of the p-layer. For this lateral injection laser, it is observed that there is a reduction of threshold currents by a factor of 2. Moreover, when the current injection changes from vertical mode to lateral mode, only slightly reduction of output power and differential quantum efficiency are found.

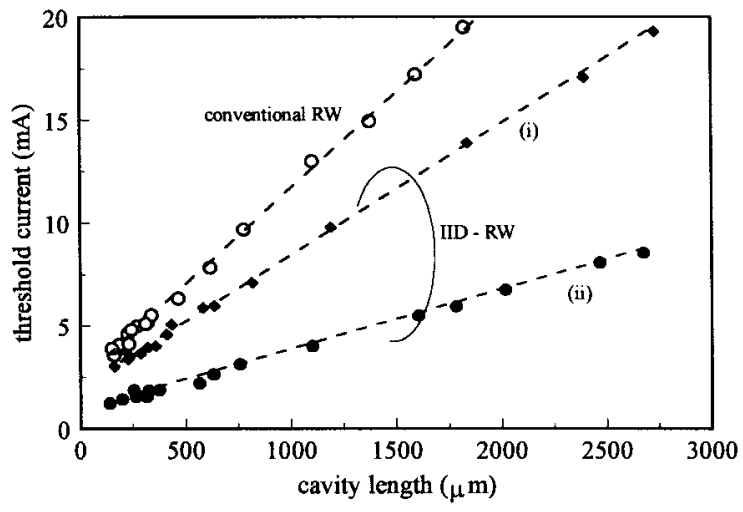

Fig. 6. Cavity-length dependence of the measured threshold currents for both conventional RW and IID-RW devices, tested under pulsed condition at room temperature. The physical stripe width for the conventional RW laser is 3 $\mu \mathrm{m}$; while it is 4 and $1.5 \mu \mathrm{m}$ for the IID-RW lasers along the lines i) and ii), respectively. However, the effective active stripe widths for these IID-RW devices are 3 and $0.7 \mu \mathrm{m}$, respectively.

Threshold current of RW lasers can be reduced significantly by using silicon-induced disordering to improve the lateral confinement of carrier concentration. This can be done by depositing silicon film outside the RW region of the conventional RW lasers for the interdiffusion process [35], [38]. The sample is sealed into an evacuated ampoule with excess arsenic to provide over-pressure and the disordering process is carried out at $850{ }^{\circ} \mathrm{C}$ for $40 \mathrm{~min}$. The diffusion of silicon defines the lateral distribution of the active stripe width of the RW laser. It is noted that the diffusion increases with the decrease of active stripe width. The sample also goes through zinc diffusion with windows opened on the ridge-top for carrier injection. Fig. 5 shows the schematic of an IID InGaAs-GaAs QW's RW laser using silicon and zinc. It is shown in [35] that the internal losses and internal quantum efficiencies for the conventional RW lasers are $3.46 \mathrm{~cm}^{-1}$ and $85.0 \%$ and for IID RW lasers are $2.82 \mathrm{~cm}^{-1}$ and $82.1 \%$, respectively. This indicates that internal loss is improved and the internal quantum efficiency is only slightly degraded. Fig. 6 compares the cavity length dependence of threshold current for devices with and without IID [35]. As we can see, the IID technique has a significant reduction of threshold current due to the current confinement properties of Si impurities diffused into the active layer. This is because IID RW lasers has significant reduction of leakage current especially for device with long cavity length.

\section{B. Lateral Optical and Electrical Confinement Using IID Technique-Neutral Impurities}

In the above examples, active impurities (i.e., silicon and zinc) are used for the fabrication of IID QW semiconductor lasers. In fact, neutral impurities such as oxygen can be utilized to enhance the lateral current confinement in lasers. For example, buried heterostructure graded barrier GaAs-AlGaAs QW's IID lasers use oxygen as the implantation impurities [36]. This can be done by using semiinsulating characteristics of oxygenimplanted AlGaAs layers to achieve lateral current confinement for the devices. In the fabrication process, it is observed that with low-dose implants of oxygen, lateral carrier diffusion is suppressed but there is no compositional disordering. On 


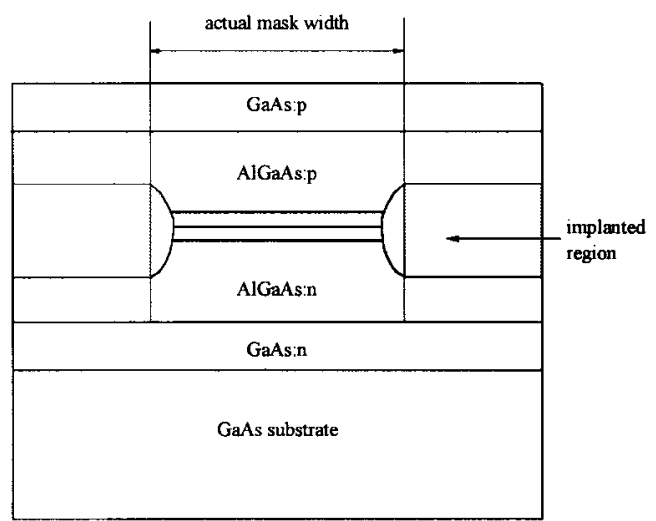

Fig. 7. Schematic cross section of laser grown by MOCVD for oxygen implantation.

the other hand, with high-dose implants, both semiinsulating and compositionally disordered region are formed, leading to index-guided buried-heterostructure laser operation. The schematic diagram of the laser structure is shown in Fig. 7. Ion-implantation is performed in a Vande Graaff accelerator at a fixed beam energy, current and implant temperature. The implanted samples are then annealed in MOCVD reactor under arsine over-pressure at $850{ }^{\circ} \mathrm{C}$ for $45 \mathrm{~min}$. The experimental results show that threshold current of the oxygen implanted is lower than that with $\mathrm{SiO}_{2}$ defined oxide stripe lasers for stripe width larger than $5 \mu \mathrm{m}$ [36]. In addition, stable fundamental mode operation can be maintained at injection current of five times its threshold value for the oxygen implanted graded barrier QW heterostructure lasers. Hence, IID method can also be used to fabricate wide-stripe high-power laser operating at single fundamental mode operation.

\section{VCSEL's Using IID}

Apart from the fabrication of facet emitting devices, IID technique has also been applied to fabricate lasers of surface emitting type. It has been shown that zinc IID technique can be used to define active region of a vertical-cavity surfaceemitting laser (VCSEL). Zinc IID is applied to disorder the perimeter of the QW active region of VCSEL's with modified dielectric-aperture such that the lateral carrier confinement is enhanced. The schematic of the GaAs-AlGaAs QW's VCSEL [12] is shown in Fig. 8. Thick $\mathrm{SiO}_{2}$ is first patterned into dots and stripes for use as dry etching and diffusion masks. Dots become the pillars of the VCSEL while stripes form the ridges. $\mathrm{Cl}_{2} \mathrm{RIE}$ are used to etch pillars through the AlAs undercut layer, followed by selective undercut etching to form an air-gap aperture. The sample undergoes a low temperature $\left(600^{\circ} \mathrm{C}\right)$ zinc diffusion for $25 \mathrm{~min}$. After the diffusion, highly conductive surface layer of zinc diffused pillar is removed by an isotropic wet etch such that the p-zinc DBR/n-DBR parasitic p-n junction area is minimized. In addition, the structure becomes planarized with contact metallization formed. The last step of the fabrication process is to evaporate an antireflection coating of $\mathrm{SiO}_{2}$ on the substrate backside.

Comparing the CW characteristics of the IID-VCSEL and the air-gap apertured VCSEL, their threshold and efficiency are

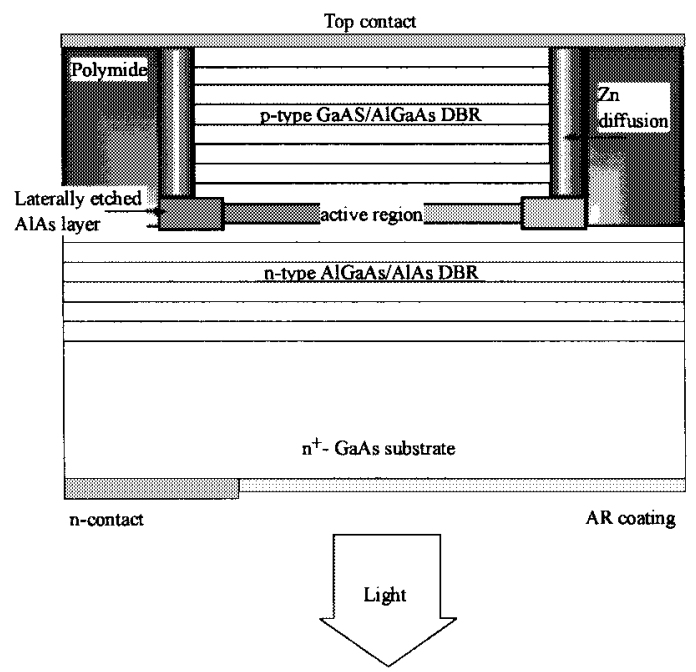

Fig. 8. Device structure of Zn IID-defined VCSEL.

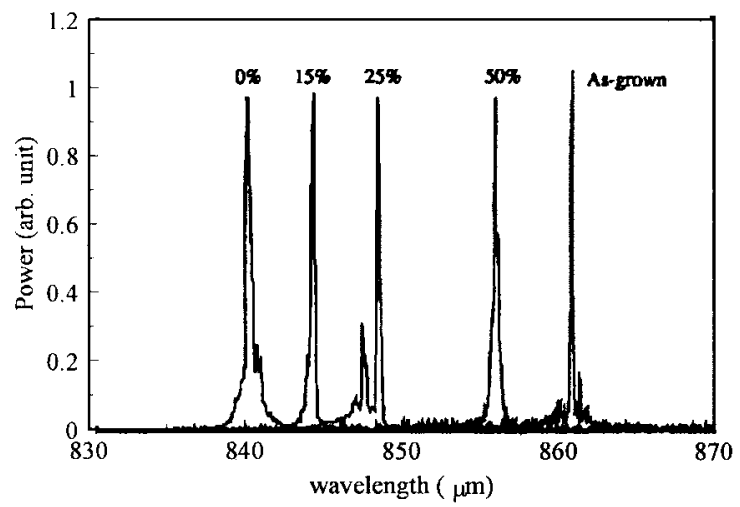

Fig. 9. Lasing spectra of lasers bandgap-shifted using selective intermixing in selected areas technique.

similar which implies IID technique has no degradation of the devices' performance. Also, it is found that Zn-IID enhances the lateral confinement of injection carrier such that IID technique can be applied in creating device of smaller diameter.

\section{Wavelength Tuning in Semiconductor Lasers Using IFVD}

The absorption band edge of QW materials can be spatially controlled across a wafer to allow the fabrication of multiple wavelength lasers [7], [22]-[30]. This control can be achieved by QW intermixing techniques such as IID and IFVD. One major advantage of IFVD over IID in fabrication of multiple wavelength lasers is free of impurity such that the increase in optical loss due to free-carrier absorption can be avoided. Therefore, output efficiency of multiple wavelength lasers using IFVD is expected to be much higher than IID devices. In the following paragraphs, the possible technique to fabricate multiple wavelength lasers using IFVD are discussed.

Spatial control of intermixing has been demonstrated to fabricate multiple wavelength lasers. This can be achieved by using small pattern of $\mathrm{SrF}_{2}$ as a bandgap control mask in conjunction with a $\mathrm{SiO}_{2}$ layer. Lasers with different lasing wavelength can be achieved with intermixing under different percentages coverage of $\mathrm{SrF}_{2}$. Fig. 9 shows the lasing 


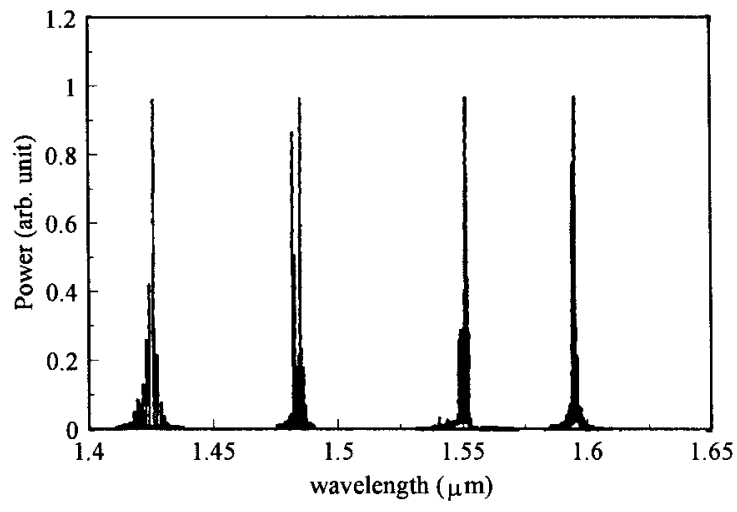

Fig. 10. Emission spectra of bandgap-tuned oxide stripe lasers.

spectra of GaAs- $\mathrm{Al}_{0.2} \mathrm{Ga}_{0.8} \mathrm{As}$ double QW's semiconductor laser with different degree of intermixing [28]. Five different wavelengths of $861,855,848,844$, and $840 \mathrm{~nm}$ correspond to $\mathrm{SrF}_{2}$ coverage of $100,50,25,15$, and $0 \%$, respectively. These lasers show only small changes in their infinite length threshold current density, and no correlation could be found between the degree of intermixing and the current density. The internal quantum efficiency of the intermixed material is a few percent lower than the as-grown material. Therefore, it is concluded that the quality of the material remains good after being intermixed using this IFVD technique of selective intermixing in the selected areas.

Multiple wavelength semiconductor lasers fabricated within a QW wafer can also be achieved by PAID. Fig. 10 shows the output spectra of the oxide stripe InGaAs-InGaAsP QW's semiconductor lasers after different degree of intermixing [7]. The laser wavelength is blue shifted as much as $160 \mathrm{~nm}$. It is observed from the lasing spectra that the gain envelope of the material is not measurably broadened. This shows that all wells are equally disordered, irrespective of the depth within the epitaxial structure. This phenomenon is due to the thermal nature of the disordering process and the close spacing of the wells. Furthermore, it is noted that the threshold current is increased with the degree of interdiffusion (i.e., blue shifted of wavelength) which is mainly due to the well shape changing and the electrons and holes becoming less confined within the wells, leading to the emission properties closer to those of bulk material. However, the internal quantum efficiency remains substantially unaffected by the PAID process.

\section{Optical Properties of Diffused Quantum Wells}

The performance of semiconductor lasers is dependent on the optical gain and background refractive index of QW material. Furthermore, the compositional disordering alters the band structure of the as-grown QW such that the optical gain and background refractive index spectra are affected. Therefore, it is expected that the performance of semiconductor lasers is also affected by interdiffusion. In order to utilize the unique properties of interdiffusion in semiconductor lasers, the optical gain and background refractive index of diffused QW have to be clarified.

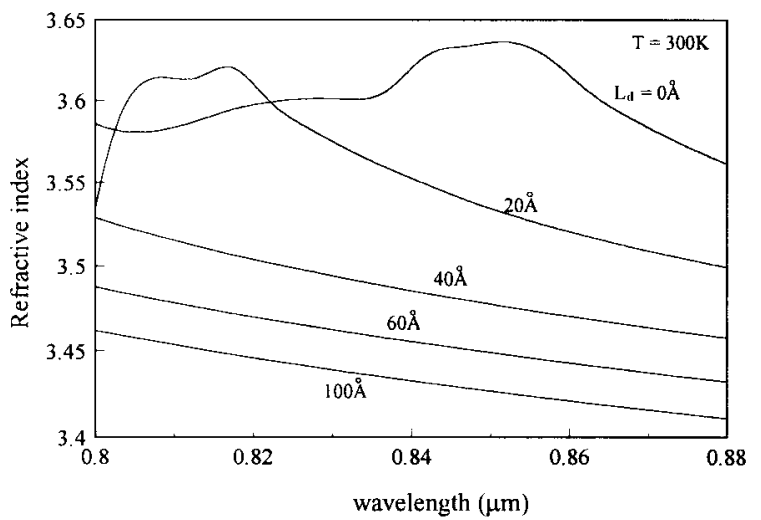

Fig. 11. Influence of interdiffusion on background refractive index spectra (TE polarization).

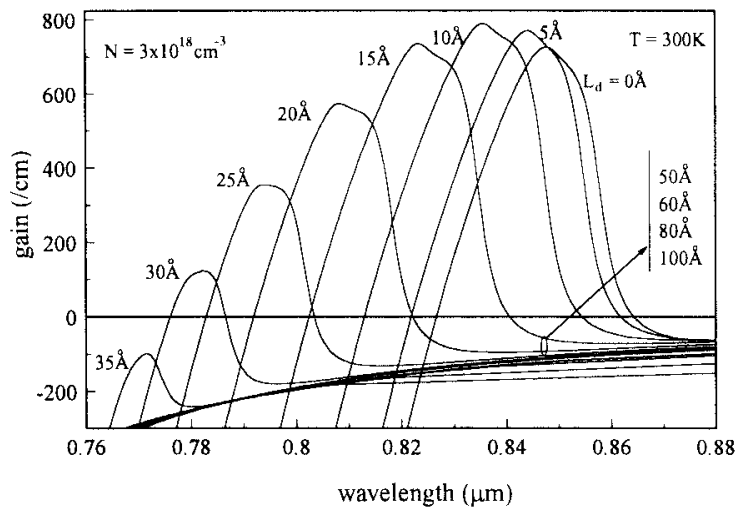

Fig. 12. Optical gain at injection carrier concentration, $N$, set to $3 \times 10^{18}$ $\mathrm{cm}^{-3}$.

\section{A. Optical Properties of GaAs-Al $l_{0.3} G a_{0.7}$ As Diffused $Q W$}

As an example, the optical properties of $\mathrm{GaAs}-\mathrm{Al}_{0.3}$ $\mathrm{Ga}_{0.7}$ As diffused QW at $300 \mathrm{~K}$ are studied. It is assumed that the well width and barrier thickness of the corresponding as-grown QW are equal to 100 and $280 \AA$, respectively. Interdiffusion is achieved by implantation of zinc impurities and followed by rapid thermal annealing. The diffusion profile of the aluminum composition across the QW structure can be determined by the Fick's Law of diffusion such that the shape of QW as well as the wavefunctions of electrons and holes can also be calculated [40]. In the model, the effect of interdiffusion is characterized by a diffusion length, $L_{d}$, where $L_{d}=0 \AA$ represents the as-grown QW. Furthermore, the detailed modeling of optical gain and background refractive index spectra can be found in [41], [42]. Fig. 11 shows the influence of interdiffusion on the background refractive index spectra (TE polarization). In general, the refractive index decreases with the increase of $L_{d}$ for wavelength larger than $0.85 \mu \mathrm{m}$. Fig. 12 shows the optical gain at injection carrier concentration, $N$, set to $3 \times 10^{18} \mathrm{~cm}^{-3}$. It is observed that as $L_{d}$ increases from 0 to $35 \AA$, the gain peak shifts to the shorterwavelength side (from 0.85 to $0.77 \mu \mathrm{m}$ ). The magnitude of the gain peak, $G_{p}$, increases slightly to a maximum value, and then decreases beyond $L_{d}=10 \AA$ until $L_{d}$ reaches 35 $\AA$, where no gain appears. In fact, at $L_{d}=30 \AA$, the gain peak reduces to $1 / 5$ of the as-grown $\mathrm{QW}$ and the explanation 


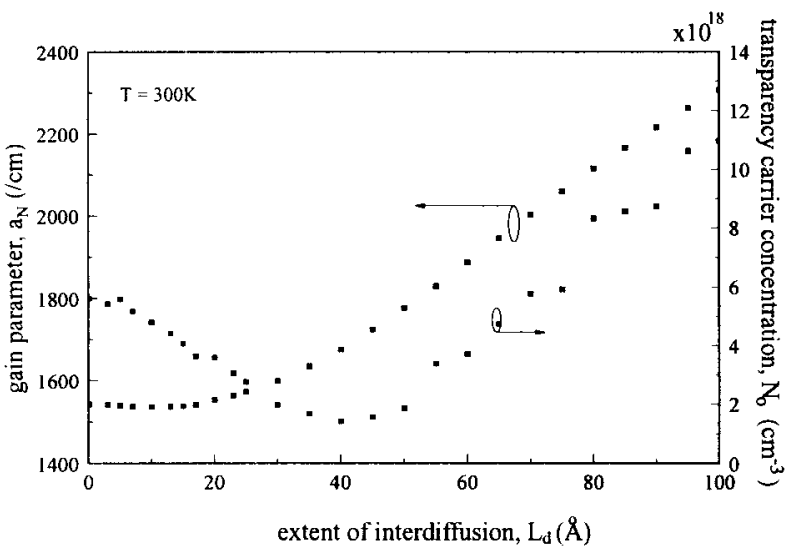

Fig. 13. Variation of gain coefficient and transparency carrier concentration with $L_{d}$ (at $\left.300 \mathrm{~K}\right)$.

can be found in [42]. For $L_{d}$ greater than $50 \AA$, no gain peak occurs and the magnitudes become almost constant over the range of wavelength.

\section{B. Approximation on Optical Properties of GaAs- $A l_{0.3} G a_{0.7}$ As Diffused $Q W$}

In device engineer viewpoint, the carrier concentration at transparency, magnitude and gain-peak wavelength are usually extracted from the optical gain spectra for the analysis of semiconductor lasers. Therefore, simple relationship between optical gain peak and injection carrier concentration is derived for the application in laser design. Using the approach in [41], the gain peak, $G_{p}$, and injection carrier concentration, $N$, can be fitted by a logarithmic relation with different magnitude of $L_{d}$ as

$$
G_{p}=a_{N}\left(1+a_{1} T+a_{2} T^{2}\right) \ln \left[\frac{N}{N_{o}\left(1+b_{1} T\right)}\right]
$$

where $T(\geq 300 \mathrm{~K})$ is the temperature, the parameters $a_{N}$ $\left(\mathrm{cm}^{-1}\right)$ and $N_{o}\left(\mathrm{~cm}^{-3}\right)$ are the gain coefficient and carrier concentration at transparency, respectively. In (1), $a_{N}$ and $N_{o}$ are assumed to vary with $L_{d}$ and their dependence on $L_{d}$ are given in [42]. Fig. 13 shows the variation of gain coefficient, $a_{N}$, and transparency carrier concentration, $N_{o}$ with $L_{d}$ (at $300 \mathrm{~K})$. The temperature dependence of $G_{p}$ is approximated by the coefficients $a_{1}=3.0815 \times 0^{-3} \mathrm{~K}^{-1}, a_{2}=5.3170 \times 10^{-6}$ $\mathrm{K}^{-2}$, and $b_{1}=6.0170 \times 10^{-3} \mathrm{~K}^{-1}$.

It is noted in our analysis that the gain-peak wavelength, $\lambda_{p}$, is nearly clamped at a fixed value for $N$ larger than $3 \times 10^{18} \mathrm{~cm}^{-3}$ but less than $10 \times 10^{18} \mathrm{~cm}^{-3}$. Therefore, the dependence of $\lambda_{p}$ on $N$ is ignored in our consideration. Fig. 14 shows the variation of $\lambda_{p}$ with $L_{d}$ at $300 \mathrm{~K}$. It is observed that $\lambda_{p}$ decreases with $L_{d}$ varying from 10 to $100 \AA$. At this range of $L_{d}$, the relation between $\lambda_{p}$ and $L_{d}$ at $300 \mathrm{~K}$ can be approximated by:

$$
\lambda_{p}=\lambda_{o}-\lambda_{N} \log \left(L_{d} / L_{o}\right)
$$

where $\lambda_{o}(\approx 0.9352 \mu \mathrm{m})$ and $\lambda_{N}(\approx 0.04818 \mu \mathrm{m})$ are the fitting parameters and $L_{o}(=1 \AA)$ is a normalizing number.

In the above analysis, we have shown the dependence of optical gain and refractive index on the degree of interdiffusion

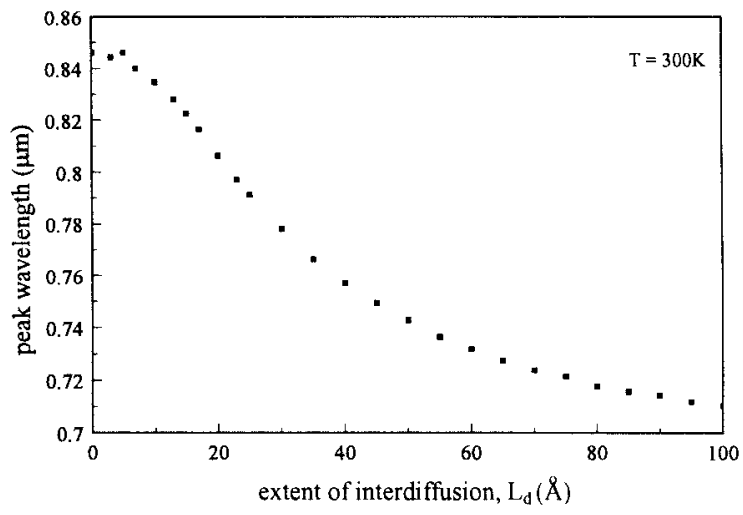

Fig. 14. Variation of $\lambda_{p}$ with $L_{d}$ at $300 \mathrm{~K}$.

(i.e., interdiffusion length, $L_{d}$ ). It is obvious that the reduction of refractive index due to interdiffusion can be used to enhance lateral optical confinement in semiconductor lasers. Furthermore, the shift of gain-peak wavelength can be utilized in multiple wavelength lasers of wide tuning range (i.e., several hundred of $\mathrm{nm}$ ) in the same wafer. In fact, these unique properties of diffused QW's have been utilized to realize semiconductor lasers and have been discussed in the above sections. On the other hand, it is noted that at some range of $L_{d}$, the diffused QW's can provide enough optical gain for lasing purpose, but the refractive index of the material can be varied significantly. For these reasons, interdiffusion technique can be used to suppressed any variation of refractive index arise from spatial-hole burning (SHB) or thermal heating such that stable single-mode operation can be achieved in semiconductor lasers. The possibility of using diffused QW's to improve laser performance are analyzed and discussed in the following sections.

\section{PROPOSED APPLICATION OF INTERDIFFUSION TECHNIQUE IN FABRICATION OF SEMICONDUCTOR LASERS WITH NOVEL STRUCTURES}

As we can see from the above sections, there are two major applications of the interdiffusion technique in fabrication of lasers: 1) minimization of threshold current by the enhancement of lateral electrical and optical confinement of lasers and 2) selectivity of the operating wavelength by variation of bandgap energy of the diffused QW's. In fact, highpower stable single-mode operation of semiconductor lasers can also be realized by using interdiffusion technique. In the following sections, the methods to maintain stable single-mode operation in: 1) Fabry-Perot; 2) distributed feedback (DFB); and 3) vertical-cavity surface-emitting semiconductor lasers by interdiffusion technique are proposed and analyzed.

\section{A. Fabry-Perot Lasers Using a Periodic Diffused $Q W$ Structure}

Fig. 15 shows the schematic diagram of a Fabry-Perot laser with periodic diffused QW structure [43]. A periodic variation of gain and refractive index (along the longitudinal direction of active region) is obtained by periodic interdiffusion. The as-grown QW section ( $L_{d}=0 \AA$ ) serves as gain region while 


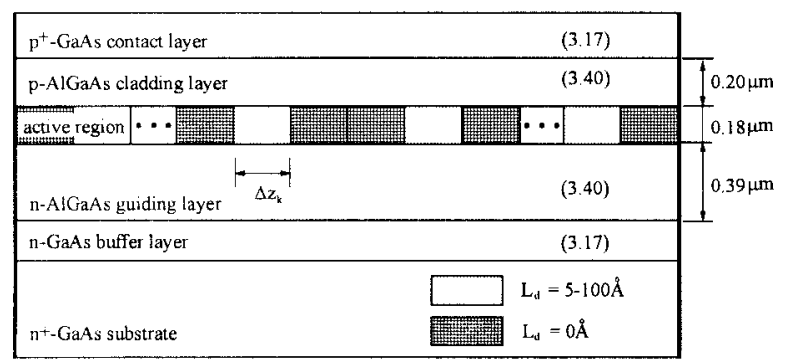

Fig. 15. Schematic diagram of a FP laser with periodic diffused QW structure.

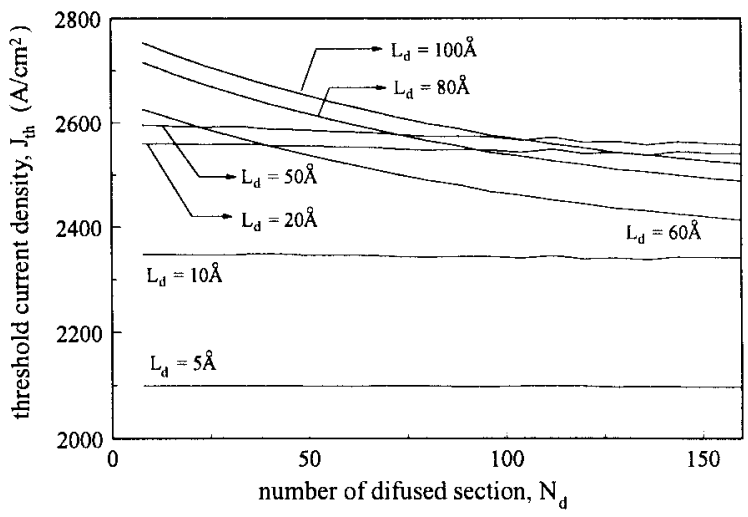

Fig. 16. A plot of threshold current density of periodic diffused QW FP laser against $N_{d}$ by varying $L_{d}$.

the diffused section $\left(L_{d}=5-100 \AA\right)$ serves as loss region with large differences of refractive index as well as optical gain. The longitudinal length of each diffused section, $\Delta z_{k}$ (for $k=1,2, \cdots, N_{d}$ ), is equal to a multiple of $\lambda_{p} / 4$, where $N_{d}$ is the total number of diffused sections. The device total length is $400 \mu \mathrm{m}$ long with $N_{d}$ varying between 8 and 160 which can be done by alternating the period of the diffusion grating. The left and right facet reflectivities of the laser cavity are equal to 0.55 .

Fig. 16 shows a plot of the threshold current density, $J_{\text {th }}$, of the periodic diffused QW FP laser against the total number of diffused sections, $N_{d}$, with $L_{d}$ as a variable parameter. It is found that for large $L_{d}(>50 \AA), J_{\mathrm{th}}$ is inversely proportional to $N_{d}$. In addition, a maximum $J_{\text {th }}$ is located at $L_{d}$ combination approximately equal to $0 \mid 100 \AA$ for $N_{d}<80$ and equal to $0 \mid 50$ $\AA$ for $N_{d}>80$. This is because the optical DFB is affected by the design of periodic diffused QW structure. It is noted from the above section that optical gain at $0.85 \mu \mathrm{m}$ can only be obtained by external carrier injection for diffused QW with $L_{d}<15 \AA$. For $L_{d}>60 \AA$, optical feedback is enhanced due to the large difference in gain and refractive index between grating sections. Therefore, low threshold current density can be obtained at $L_{d}<10 \AA$ or $L_{d}>60 \AA$ and is also a function of $N_{d}$. It must be noted that the threshold current density of Fabry-Perot lasers without periodic diffused QW structure is equal to $2123 \mathrm{~A} / \mathrm{cm}^{2}$. Fig. 17 shows the corresponding threshold amplified spontaneous spectra for $L_{d}$ 's combination equals to $0 \mid 10$ and $0 \mid 60 \AA$ (with $N_{d}$ equals to 24 and 96). As shown in the figure, bandgap mode is dominant in the spectra especially for $L_{d}$ 's combination equal to $0 \mid 60 \AA$ and $N_{d}=$

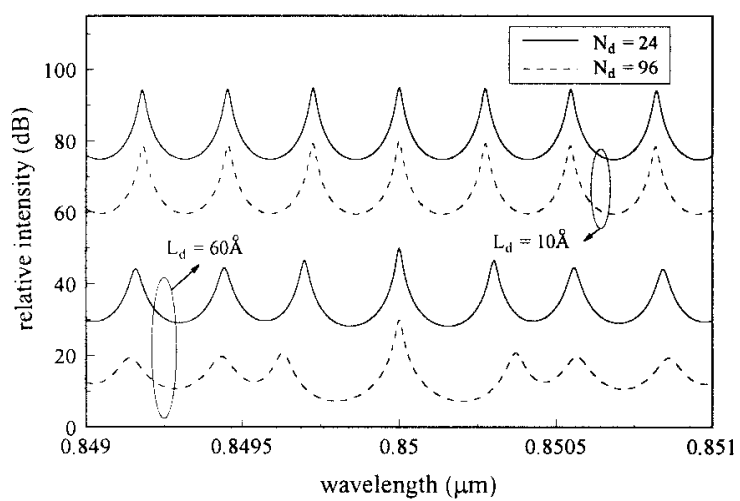

Fig. 17. Threshold emission spectra of diffused QW's FP lasers for $L_{d}=$ $0 \mid 10$ and $0 \mid 60 \AA, N_{d}=24$ and 96 .

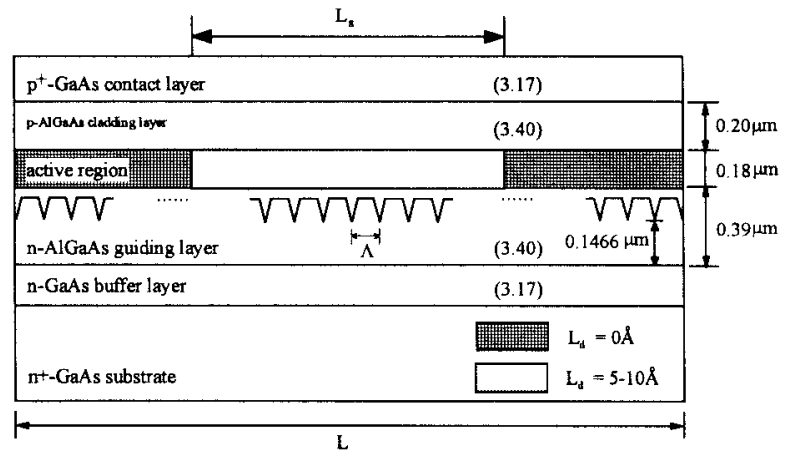

Fig. 18. Laser structure of DFB laser with diffusion step.

96. This is expected as the filtering properties of the periodic DFQW's structure are more efficient for large magnitude of $L_{d}$ and $N_{d}$. As we can see, with suitable application of periodic diffused QW's structure, stable single-longitudinal mode operation in Fabry-Perot lasers can be maintained. In fact, similar periodic diffused QW's structure has been utilized to maintain single-longitudinal-mode operation in DFB lasers [44].

\section{B. DFB Lasers Using a Step-Diffused QW Structure}

The laser structure under analysis is shown in Fig. 18. A phase-adjustment region (PAR) is formed by the introduction of a diffusion step into the center of the active region [43]. The optical gain and refractive index of the PAR are slightly less than that of the as-grown region. In order to produce a $\lambda / 4$ phase-shifted structure, we set the product of propagation-coefficient difference and effective length of the PAR to $\pm(1 / 2+n) \pi$ [45], [46]. The advantage of using interdiffusion technique in forming PAR is that it needs only simple fabrication procedures. It is because we can easily get diffused QW structure by impurities implantation and thermal annealing.

In Fig. 19, the graph of side mode suppression ratio (SMSR) against normalized current density is shown. Two kinds of lasers at steady state are analyzed, with step diffusion profile $\left(L_{d}=5 \AA\right.$ ) and without that profile (conventional discrete $\lambda / 4$ DFB laser). It is clearly seen that with step diffused profile, the device exhibits single longitudinal operation. However, 


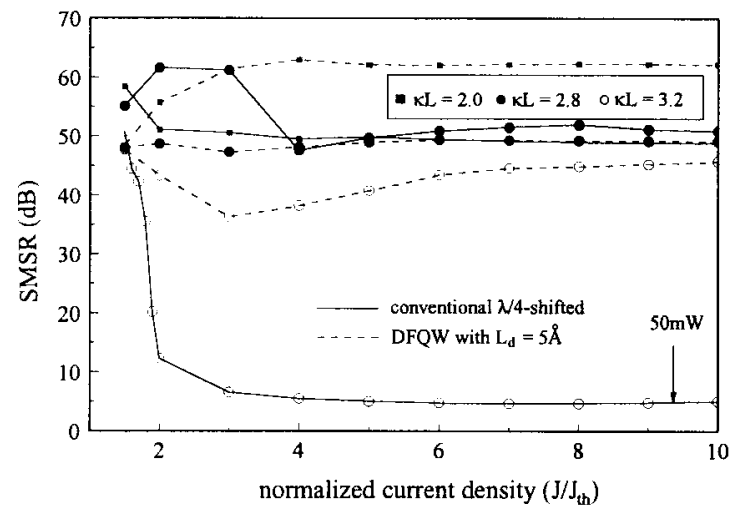

Fig. 19. A plot of side mode suppression ratio (SMSR) varied with normalized current density with $k L=2,2.8$, and 3.2.

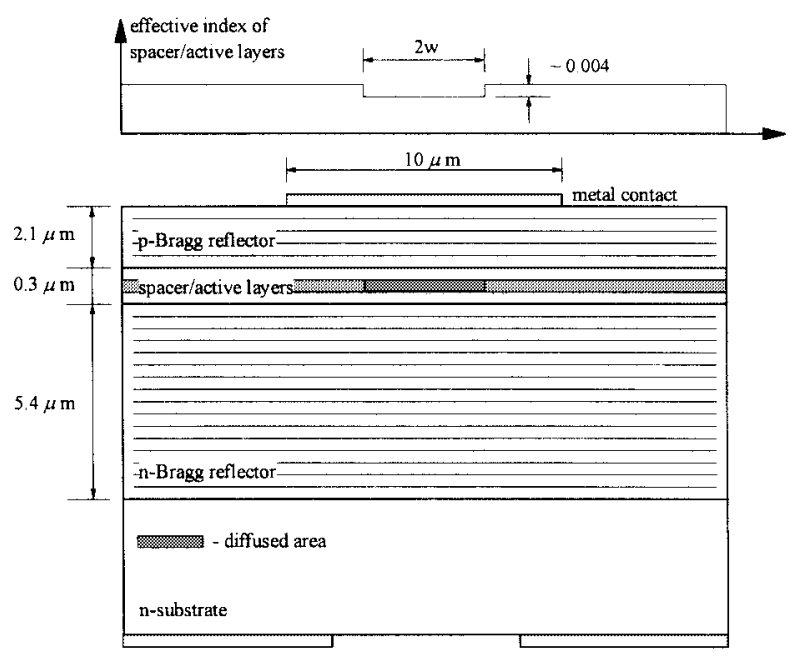

Fig. 20. Schematic diagram of VCSEL with diffused QW's structure.

for conventional $\lambda / 4$ DFB device, multimode operation is observed, as there is a drop of SMSR from 50 to $10=40$ $\mathrm{dB}$. It is because the built-in step refractive index profile is against the carrier-induced index change inside the active region. From the graph, it is proved that when normalized current density $\left(J / J_{\mathrm{th}}\right)=10$, the maximum output power is greater than $50 \mathrm{~mW}$. For device with $L_{d}=10 \AA$, similar results would be obtained. In order to minimize the influence of SHB, the value of $L_{d}$ should be between 5 and $10 \AA . L_{d}$ cannot be smaller than $5 \AA$ as it is not realistic owing to the controllability of interdiffusion. Also, for $L_{d}>10 \AA$, the built-in refractive index becomes larger than that required in overcoming the SHB effects. Thus, it can be concluded that a reasonable range is $5 \AA<L_{d}<10 \AA$, and it would give good result in minimizing SHB effects in DFB lasers at high output power.

\section{VCSEL's with a Step Diffused QW Structure}

VCSEL's are found to exhibit multiple transverse modes operation at high power. The multiple transverse modes are excited by the increase in refractive index, which is caused by carrier SHB and thermal lensing. As a result, the performance of the lasers will be deteriorated. In order to achieve high-

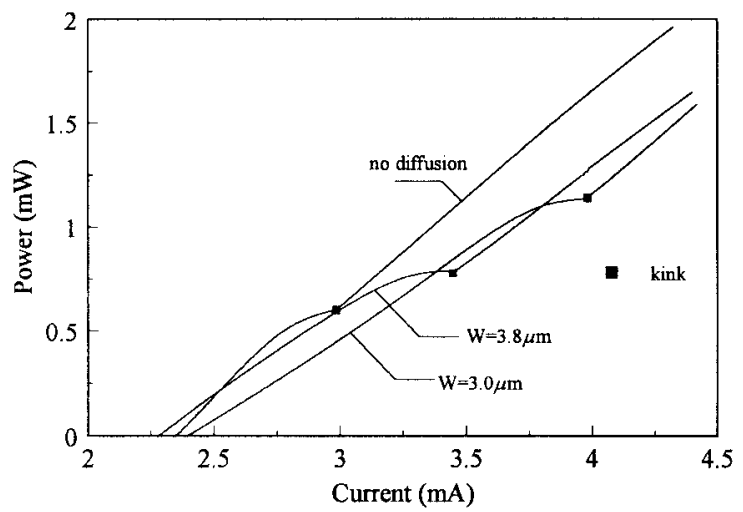

Fig. 21. $L-I$ characteristics of VCSEL with and without step-diffused QW structure.

power single-longitudinal-mode operation, it is proposed to use VCSEL with diffused QW. The schematic diagram of VCSEL with diffused QW structure is shown in Fig. 20 [47]. Step diffused QW structure is introduced along the active layer by IID. Impurities are implanted into the core region of the active layer through the p-Bragg reflector. The cladding region is shielded by a circular mask to avoid the influence of interdiffusion. After implantation, RTA is applied to induce compositional disordering and to restore the impurities damage. Consequently, a small refractive index step is established between the core and cladding region. Thus, an anti-index guided structure is obtained.

A plot of light power against current is as in Fig. 21, with radius of diffusion area, $W$, equals 3 and $3.8 \mu \mathrm{m}$. Device without diffusion is also shown in the figure for comparison. It is observed that a kink is presented for both cases with the excitation of first-order mode. This is because of the selffocusing effects, arising from the increase of refractive index inside the core region of the active layer at high power due to 1) SHB of carrier concentration and 2) the influence of thermal lensing, increase the optical gain of first-order mode as it is focused toward the core region. However, for lasers with stepdiffusion introduced, the increase in refractive index inside the core region is counteracted by the step diffused QW structure. Therefore, kink is shifted upward and stable fundamental mode operation is maintained at high power.

\section{Diffused QW VCSEL's for Self-Sustained Pulsation}

It is expected that VCSEL can exhibit self-sustained pulsation (SSP) owing to its lateral confinement structure and lateral overlap effects. However, as the laser cavity of VCSEL is small, the lateral loss effects resulted (i.e., self-focusing, diffraction loss, SHB and thermal lensing) dominate over lateral overlap effects (i.e., overlap volume between saturable region and lasing mode) and SSP is suppressed. Recently, it is proposed to introduce diffused QW structure by compositional IID into VCSEL to enhance SSP [48]. The proposed structure of the VCSEL with diffused QW structure is similar to Fig. 20 except the metal contact has the same area as the diffused region. The use of diffused $\mathrm{QW}$ in the active region and the as-grown QW in the lateral cladding region has the following reasons: 1) the diffused QW active region is slightly 


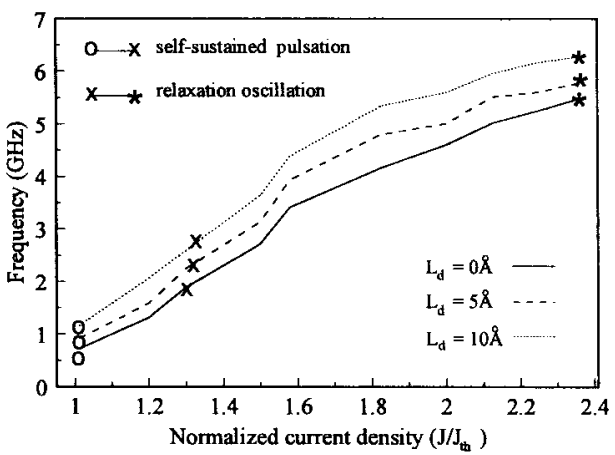

(a)

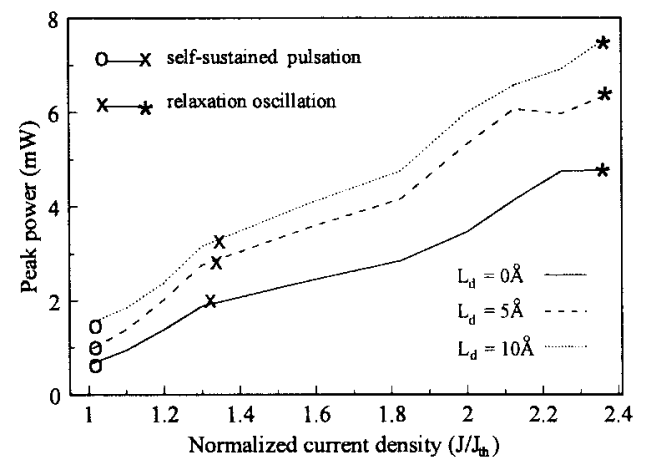

(b)

Fig. 22. Current dependence of (a) pulse repetition frequency and (b) output power for VCSEL with $W=1.3 \mu \mathrm{m}, L_{d}=0,5$, and $10 \AA$.

blue-shifted relative to the saturable absorber cladding for enhanced SSP and, more importantly, 2) the structure becomes antiguiding and, therefore, allows for a larger aperture, thereby reducing lateral loss effect. Hence, SSP can be enhanced in VCSEL's by diffused QW's structure.

It should also be noted that large value of $L_{d}$ can increase the overlap volume between saturable absorption region and lasing mode. However, $L_{d}$ should be kept below $10 \AA$ with a view to preserve the optical gain inside the core region. The repetition frequency and peak power of the device is investigated, with core radius equals $1.3 \mu \mathrm{m}$. The results are shown in Fig. 22. It can be seen that the increase of $L_{d}$ results in the enhancement of repetition frequency and peak power for both SSP and relaxation oscillation (RO). Thus we can conclude that the introduction of diffused QW not only helps the exhibition of SSP, but also helps in the enhancement of repetition frequency and peak power.

The transient response of VCSEL's with diffused QW's structure are also studied under large signal modulation [49]. The $L P_{01}$ and $L P_{11}$ modes at RO and SSP operations are shown in Fig. 23. The magnitude of $L_{d}$ at the cladding and core regions are assumed equal to 0 and $5 \AA$, respectively. In addition, the radius of the core region is set to $1.4 \mu \mathrm{m}$ for RO and $1.2 \mu \mathrm{m}$ for the excitation of SSP. The corresponding transient response of the lateral carrier distribution is also shown in Fig. 24. In both cases (i.e., RO and SSP), the transient responses of carrier concentration in the core and cladding regions are operated out of phase. This is because the generation of lasing power, due to the increase

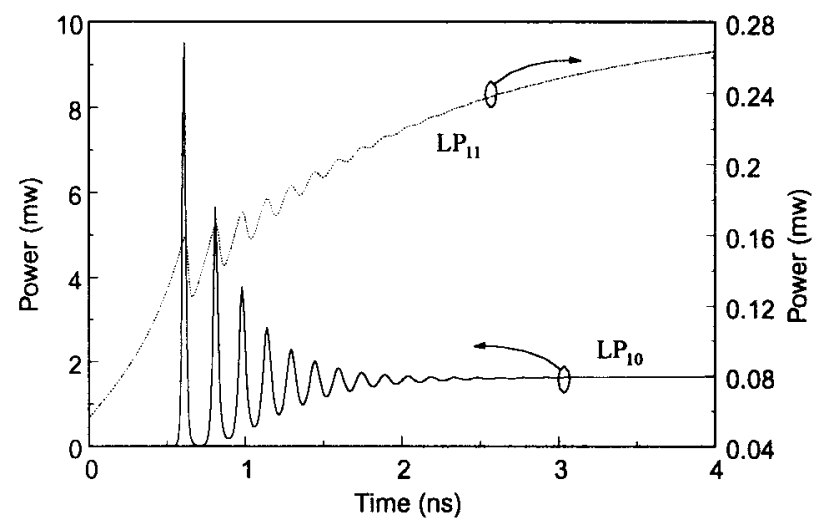

(a)

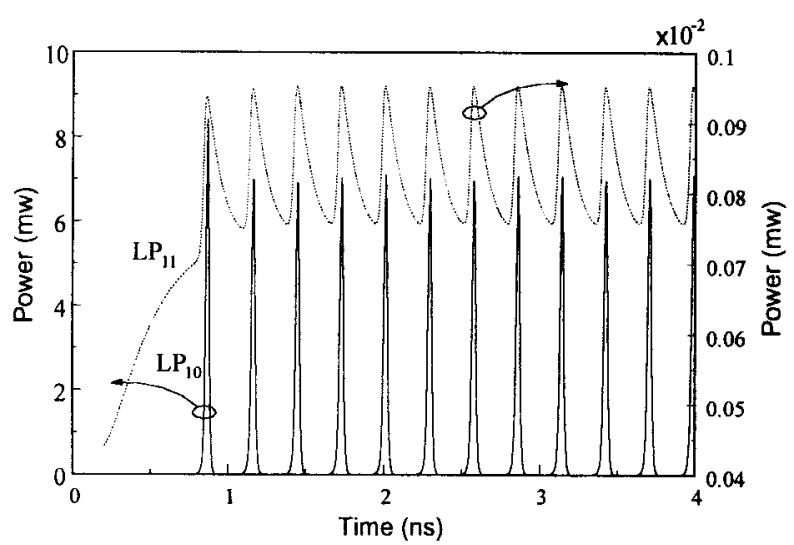

(b)

Fig. 23. Transient response of output power of VCSEL's at (a) relaxation oscillation and (b) self-sustained pulsation operations. Solid line $-L P_{01}$ mode and dotted line- $L P_{11}$.

of carrier concentration inside the core area, is absorbed in the cladding region. As a result, a reduction in carrier concentration inside the cladding region is obtained. The main different between RO and SSP is the lateral distribution of carrier concentration. In Fig. 7(b), at time equals " $T_{s}$ " (i.e., just before the simulation recombination occurs), the lateral distribution of carrier concentration maintains at a single-lobe profile which maximizes the optical gain of the $L P_{01}$ mode. However, in the transient of RO, lateral spatial hole burning is established which may enhance the excitation of $L P_{11}$ or higher order modes. Therefore, the enhancement of SSP in VCSEL's by using diffused QW's structure also supports single-mode operation.

\section{DISCUSSION AND CONCLUSION}

The success of using diffused QW's structures to fabricate high-performance semiconductor lasers depends upon whether the interdiffusion technique is compatible with the existing fabrication techniques such that the production cost and wastage in devices' fabrication can be further reduced. In fact, the possibility to realize diffused QW's structure depends upon the following criteria.

- The proposed semiconductor lasers have typical dimensions which required simple processing technique and are compatible with existing fabrication technologies. 


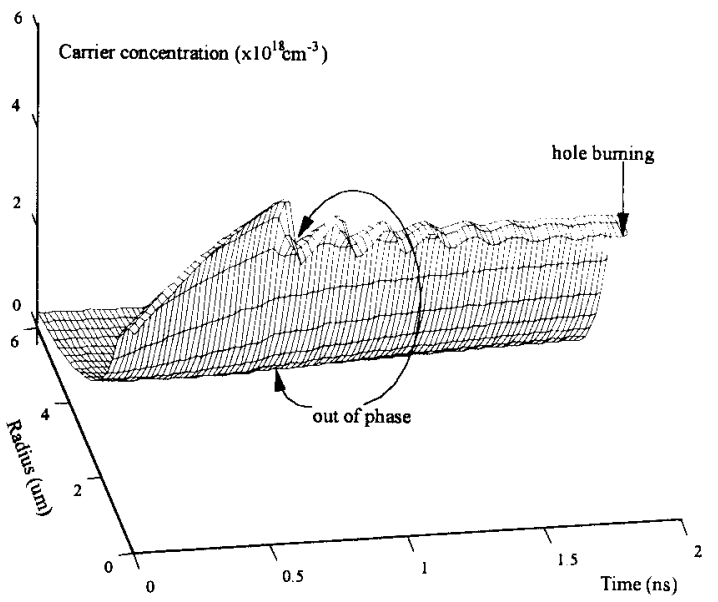

(a)

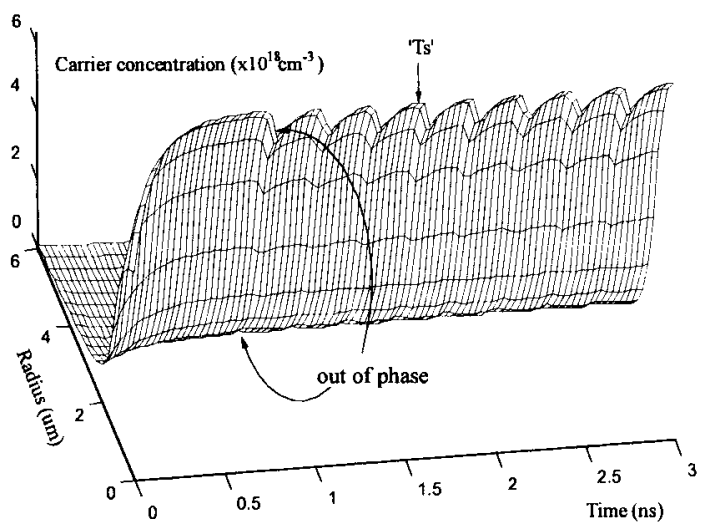

(b)

Fig. 24. The corresponding transient response of carrier concentration at (a) relaxation oscillation and (b) self-sustained pulsation operations.

- Interdiffusion of QW's requires the penetration of impurities or vacancies into the QW active layer such that the diffusion process can be carried out. Therefore, the penetration depth of impurities or vacancies should be of same order of magnitude to the depth of QW's active layer.

- The diffusion length $L_{d}$ of diffused QW's active region is determined by the implantation energy and thermal annealing time of the interdiffusion process. With careful control of annealing temperature and time, $L_{d}$ down to $5 \AA$ can be obtained without any difficulty.

- The formation accuracy of diffusion pattern determines the yield-rate of the semiconductor lasers. The combined technologies of electron beam lithography and implantation enhanced intermixing are utilized to realize nanometer structure, which is far more precise than the required $\mu \mathrm{m}$ diffused QW's grating.

Advantages for adopting diffused QW structure are: 1) the tunability of the operating wavelength by modifying the diffusion profile; 2) the improvement of injection current confinement inside the active layer; and 3) the enhancement of the yield rate of single-mode operation in semiconductor lasers such as FP, DFB, and VCSEL's.
There are several possible research directions for using the unique features of diffused QW structure in semiconductor lasers for the future investigation. For example:

- the improvement of on-off extinction ratio and polarization sensitively in semiconductor laser-modulator [50] and;

- the enhancement of saturable absorption region in multisection mode-locked, gain switched and self-sustained pulsation semiconductor lasers for the generation of narrow pulsewidth and high-peak-power optical pulses [51].

In conclusion, the methods to implement interdiffusion in QW's materials as well as its application in semiconductor lasers have been discussed and analyzed. Apart from the controllability of lateral electrical and optical confinement or lasing wavelength tunability, it is shown that the interdiffusion technique can also be utilized to maintain stable single-mode operation in semiconductor lasers. The design criteria of diffused QW's lasers is also discussed and the results given in this paper can be utilized as a design guideline to realize high-performance semiconductor lasers.

\section{REFERENCES}

[1] W. X. Zou, J. L. Merz, R. J. Fu, and C. S. Hong, "Very-low-threshold strained $\operatorname{In}_{y} \mathrm{Ga}_{1-y}$ As-GaAs quantum-well lasers defined by impurityinduced disordering," IEEE Photon. Technol. Lett., vol. 3, pp. 400-402, 1991.

[2] R. L. Thornton, R. D. Burnham, T. L. Paoli, N. Holonyak, Jr., and D. G. Deppe, "Low threshold planar buried heterostructure lasers fabricated by impurity-induced disordering," Appl. Phys. Lett., vol. 47, pp. 1239-1241, 1985.

[3] S. R. Andrew, J. H. Marsh, M. C. Holland, and A. H. Kean, "Quantumwell laser with integrated passive waveguide fabricated by neutral impurity disordering," IEEE Photon. Technol. Lett., vol. 4, pp. 426-428, 1992.

[4] W. X. Zou, J. L. Merz, R. J. Fu, and C. S. Hong, "Ultralow threshold strained InGaAs-GaAs quantum well lasers by impurity-induced disordering," Electron. Lett., vol. 27, pp. 1241-1243, 1991.

[5] P. D. Floyd, C. P. Chao, K. K. Law, and J. L. Merz, "Low-threshold lasers fabricated by alignment-free impurity induced disordering," IEEE Photon. Technol. Lett., vol. 5, pp. 1261-1263, 1993.

[6] A. McKee, C. J. McLean, A. C. Bryce, R. M. De La Rue, C. Button, and J. H. Marsh, "High quality wavelength tuned multiquantum well GaInAs/GaInAsP lasers fabricated using photoabsorption induced disordering," Appl. Phys. Lett., vol. 65, no. 18, pp. 2263-2265, 1994.

[7] A. McKee, C. J. McLean, G. Lullo, A. C. Bryce, R. M. De La Rue, J. H. Marsh, and C. C. Button, "Monolithic integration in InGaAs/InGaAsP multiple quantum well structures using laser intermixing," IEEE J. Quantum Electron., vol. 33, no. 1, pp. 45-55, 1997.

[8] E. H. Li, Ed., SPIE's Milestone Series of Selected Reprints on the Subject Quantum Well Intermixing for Photonics. Washington, DC: SPIE, to be published.

[9] R. L. Thornton, W. J. Mosby, and T. L. Paoli, "Monolithic waveguide coupled cavity lasers and modulators fabricated by impurity induced disordering," J. Lightwave Technol., vol. 6, pp. 786-792, 1988.

[10] G. A. Vawter, D. R. Myers, M. T. Brennan, and B. E. Hammons, "Low threshold current implanted-planar buried-heterostructure gradedindex separate confinement heterostructure laser in GaAs/AlGaAs," Appl. Phys. Lett., vol. 56, pp. 1945-1947, 1990.

[11] N. H. Ky, J. D. Ganiere, F. K. Reinhart, and B. Blanchard, "Background Si-doping effects on $\mathrm{Zn}$ diffusion-induced disordering in GaAs/AlGaAs multiple-quantum-well structures," J. Appl. Phys., vol. 79, pp. 4009-4016, 1996.

[12] P. D. Floyd, B. J. Thibeault, J. Ko, D. B. Young, L. A. Coldren, and J. L. Merz, "Vertical cavity lasers with $\mathrm{Zn}$ impurity-induced disordering (IID) defined active regions," in Proc. LEOS'96, 1996, vol. 2, pp. 207-208.

[13] W. X. Zou, T. Bowen, K.-K. Law, D. B. Young, and J. L. Merz, "1.0$\mathrm{mA}$-threshold uncoated lasers by impurity-induced disordering," IEEE Photon. Technol. Lett., vol. 5, pp. 591-594, 1993. 
[14] W. X. Zou, K. K. Law, L. C. Wang, J. L. Merz, H. E. Hager, and C. S. Hong, "Unique top-driven low-threshold lasers by impurity-induced disordering," IEEE J. Quantum Electron., vol. 29, pp. 2097-2101, 1993.

[15] R. P. Bryan, J. J. Coleman, L. M. Miller, M. E. Givens, R. S. Averback, and J. L. Klatt, "Impurity induced disordered quantum well heterostructure stripe geometry lasers by $\mathrm{MeV}$ oxygen implantation," Appl. Phys. Lett., vol. 55, pp. 94-96, 1989.

[16] W. D. Laidig, N. Holonyak, and M. D. Camras, "Disorder of an AlAs-GaAs superlattice by impurity diffusion," Appl. Phys. Lett., vol. 38, pp. 776-778, 1981

[17] K. Goto, F. Uesugi, S. Takahashi, T. Takiguchi, E. Omura, and Y. Mihashi, "Zn-diffusion-induced disordering of InGaAs/AlGaInAs multiplequantum-well and its application to long-wavelength laser," Jpn. J. Appl. Phys., vol. 33, p. 5773, 1994.

[18] J. Werner, T. P. Lee, E. Kapon, E. Colas, N. G. Stoffel, S. A. Schwarz, L. C. Scheartq, and N. C. Andreadakis, "Single and double quantum well lasers with a monolithically integrated passive section," Appl. Phys. Lett., vol. 57, pp. 810-812, 1990

[19] D. G. Deppe, K. C. Hsieh, N. Holonyak, R. D. Burnham, and R. L. Thornton, "Low threshold disordered defined buried heterostructure $\mathrm{Al}_{x} \mathrm{Ga}_{1-x} \mathrm{As} / \mathrm{GaAs}$ quantum well lasers," J. Appl. Phys., vol. 58, pp. $4515-4520,1985$

[20] J. Werner, E. Kapon, N. G. Stoffel, E. Colas, S. A. Schwarz, C. L. Schwartz, and N. Andreadakis, "Integrated external cavity GaAs/AlGaAs lasers using selective quantum well disordering," Appl. Phys. Lett., vol. 55, pp. 540-542, 1989.

[21] D. R. Myers, K. Lee, T. Hausken, R. J. Simes, H. Ribot, F. Laruelle, and L. A. Coldren, "High-energy argon-ion implantation for waveguide formation in (AlGa)As/GaAs multilayers," Appl. Phys. Lett., vol. 57, pp. 2051-2053, 1990.

[22] M. O’Neill, A. C. Bryce, J. H. Marsh, R. M. De La Rue, J. S. Roberts, and C. Jeynes, "Multiple quantum well optical waveguide with large absorption edge blue shift produced by boron and fluorine impurity induced disordering," Appl. Phys. Lett., vol. 55, pp. 1373-1375, 1989.

[23] S. Charbonneau, P. J. Poole, P. G. Piva, M. Buchanan, R. D. Goldberg, and I. V. Mitchell, "Bandgap tuning of semiconductor quantum well laser structures using high energy ion implantation," Nucl. Instrum. Meth. Phys. Res. B, vol. 106, pp. 457-460, 1995.

[24] S. Charbonneau, P. J. Poole, P. G. Piva, G. C. Aers, E. S. Koteles, M. Fallahi, J. J. He, J. P. McCaffrey, M. Buchanan, M. Dion, R. D. Goldberg, and I. V. Mitchell, "Quantum-well intermixing for optoelectronic integration using high energy ion implantation," J. Appl. Phys., vol. 78, pp. 3697-3705, 1995.

[25] J. D. Ralston, S. Orien, G. W. Wick, and L. F. Eastman, "Roomtemperature exciton transitions in partially intermixed GaAs/AlGaAs superlattices," Appl. Phys. Lett., vol. 52, pp. 1511-1513, 1988.

[26] P. Cusumano, J. H. Marsh, M. J. Rose, and J. S. Roberts, "Highquality extended cavity ridge lasers fabricated by impurity-free vacancy diffusion with a novel masking technique," IEEE Photon. Technol. Lett., vol. 9, pp. 282-284, 1997.

[27] S. G. Ayling, J. Beauvais, and J. H. Marsh, "Spatial control of quantum well intermixing in GaAs/AlGaAs using a one-step process," Electron. Lett., vol. 28, pp. 2240-2242, 1992.

[28] B. S. Ooi, S. G. Ayling, A. C. Bryce, and J. H. Marsh, "Fabrication of multiple wavelength lasers in GaAs-AlGaAs structures using a one-step spatially controlled quantum-well intermixing technique," IEEE Photon. Technol. Lett., vol. 7, pp. 944-946, Sept. 1995.

[29] B. S. Ooi, K. McIlvaney, M. W. Street, A. Helmy, S. G. Ayling, A. C. Bryce, J. H. Marsh, and J. S. Roberts, "Selective quantum-well intermixing in GaAs/AlGaAs structures using impurity-free vacancy diffusion," IEEE J. Quantum Electron., vol. 33, pp. 1784-1793, Oct. 1997.

[30] S. Burkner, J. D. Ralston, S. Weisser, J. Rosenzweig, E. C. Larkins, R. E. Sah, and J. Fleissner, "Wavelength tuning of high-speed InGaAs-GaAs-AlGaAs pseudomorphic MQW lasers via impurity-free interdiffusion," IEEE Photon. Technol. Lett., vol. 7, pp. 941-944, 1995.

[31] W. J. Choi, S. Lee, Y. Kim, D. Woo, S. K. Kim, S. H. Kim, J. I. Lee, K. N. Kang, J. H. Chu, S. K. Yu, J. C. Seo, and D. Kim, "Carrier lifetimes in delectric cap disordered GaAs/AlGaAs multiple quantum well with SiN capping layers," Appl. Phys. Lett., vol. 67, no. 23, pp. 3438-3440, 1995.

[32] S. Yuan, Y. Kim, C. Jagadish, P. T. Burke, M. Gal, J. Zou, D. Q. Cai, D. J. H. Cockayne, and R. M. Cohen, "Novel impurity-free interdiffusion in GaAs/AlGaAs quantum wells by anodization and rapid thermal annealing," Appl. Phys. Lett., vol. 70, pp. 1269-1271, 1997.
[33] C. J. McLean, J. H. Marsh, R. M. De La Rue, A. C. Bryce, B. Garrett, and R. W. Glew, "Layer selective disordering by photoabsorptioninduced thermal diffusion in InGaAs/InP based multiquantum well structures," Electron. Lett., vol. 28, pp. 1117-1119, 1992.

[34] G. P. Agrawal and N. K. Dutta, Long Wavelength Semiconductor Lasers. New York: Van Nostrand Reinhold, 1986.

[35] S. Y. Hu, M. G. Peters, D. B. Young, A. C. Gossard, and L. A. Coldren, "Submilliampere-threshold InGaAs-GaAs quantum-well ridgewaveguide lasers with lateral confinement provided by impurity-induced disordering," IEEE Photon. Technol. Lett., vol. 7, pp. 712-715, 1995.

[36] R. P. Bryan, J. J. Coleman, L. M. Miller, M. E. Givens, R. S Averback, and J. L. Klatt, "Impurity induced disordered quantum well heterostructure stripe geometry lasers by $\mathrm{MeV}$ oxygen implantation," Appl. Phys. Lett., vol. 55, pp. 94-96, 1989.

[37] W. X. Zou, K. K. Law, J. L. Merz, R. J. Fu, and C. S. Hong, "Laterally injected low-threshold lasers by impurity-induced disordering," Appl. Phys. Lett., vol. 59, pp. 3375-3377, 1991

[38] S. Y. Hu, D. B. Young, S. W. Corqine, A. C. Gossard, and L. A Coldren, "High-efficiency and low-threshold InGaAs/AlGaAs quantumwell lasers," J. Appl. Phys., vol. 76, pp. 3932-3934, 1994.

[39] M. Sugimoto, N. Hamaoi, N. Takado, K. Asakawa, and T. Yuasa, "Very low threshold $\mathrm{AlGaAs} / \mathrm{GaAs}$ quantum well lasers fabricated by selfaligned impurity induced disordering," Jpn. J. Appl. Phys. Lett., vol. 28, pp. L1013-L1015, 1989.

[40] E. H. Li and B. L. Weiss, "Analytical solution of the subbands and absorption coefficients of AlGaAs-GaAs hyperbolic quantum wells," IEEE J. Quantum Electron., vol. 29, pp. 311-321, 1993.

[41] E. H. Li, B. L. Weiss, K. S. Chan, and J. Micallef, "Polarization dependent refractive index of an interdiffusion induced $\mathrm{AlGaAs} / \mathrm{GaAs}$ quantum well," Appl. Phys. Lett., vol. 62, pp. 550-552, 1992.

[42] E. H. Li and K. S. Chan, "Laser gain and current density in a disordered AlGaAs/GaAs quantum well," Electron. Lett., vol. 29, pp. 1233-1234, 1993.

[43] S. F. Yu, C. W. Lo, and E. H. Li, "High-power single-mode operation in DFB and FP lasers using diffused quantum-well structure," IEEE J. Quantum Electron., vol. 33, pp. 999-1008, 1997.

[44] V. Hofsäß, J. Kuhn, C. Kaden, V. Härle, H. Bolay, F. Scholz, H Schweizer, H. Hillmer, R. Lösch, and W. Schlapp, "Optical integration of laterally modified multiple quantum well structures by implantation enhanced intermixing to realize gain coupled DFB lasers," Nuclear Instrum. Meth. Phys. Res. B, vol. 106, pp. 471-476, 1995.

[45] H. Soda, Y. Kotaki, H. Sudo, H. Ishikawa, S. Yamakoshi, and H. Imai, "Stability in single longitudinal mode operation in GaInAsP/InP phaseadjusted DFB lasers," IEEE J. Quantum Electron., vol. 23, pp. 804-814, June 1987.

[46] J. Kinoshita, K. Ohtsuka, H. Agatsuma, A. Tanaka, T. Matsuyama, A. Makuta, and H. Kobayashi, "Performance of $1.5 \mu \mathrm{m}$ DFB lasers with a narrow stripe region," IEEE J. Quantum Electron., vol. 27, pp. 1759-1765, June 1991.

[47] S. F. Yu and P. C. Chui, "Proposed enhancement of single mode operation in VCSEL's using diffused quantum wells structure," Opt. Quantum Electron., vol. 30, pp. 71-77, 1998.

[48] S. F. Yu, "Analysis and design of vertical cavity surface emitting lasers for self-sustained pulsation operation," IEEE J. Quantum Electron., vol. 34, pp. 497-505, Mar. 1998.

[49] S. F. Yu and C. W. Lo, "Influence of transverse modes on the dynamic response of vertical cavity surface emitting lasers," in Proc. Inst. Elect. Eng.-J, Optoelectronics, vol. 143, no. 3, pp. 189-194, 1996.

[50] A. Ramdane, F. Devaux, N. Souli, D. Delprat, and A. Ougazzaden, "Monolithic integration of multiple-quantum-well lasers and modulators for high speed transmission," IEEE J. Select. Topics Quantum Electron., vol. 2, pp. 326-335, 1996

[51] A. C. Bryce, F. Camacho, and J. H. Marsh, "CW and mode-locked integrated extended cavity lasers fabricated using impurity free vacancy disordering," IEEE J. Select. Topics Quantum Electron., vol. 3, pp. 885-892, 1997.

S.-F. Yu, for photograph and biography, see this issue, p. 722

E. Herbert Li (SM'95), for photograph and biography, see this issue, p. 582. 